\title{
Contribution of host factors and workplace exposure to the outcome of occupational
} asthma

\author{
Piero Maestrelli*, Vivi Schlünssen\#, Paola Mason* and Torben Sigsgaard* on behalf \\ of the ERS Task Force on the Management of Work-related Asthma
}

ABSTRACT: The outcome of occupational asthma after diagnosis is often poor. The identification of factors associated with a worse outcome may help in the management of the disease, determining its prognosis and assessing the permanent impairment attributable to occupational exposure.

The aim of this systematic review was to provide the available evidence from the medical literature to answer the question: "What is the contribution of host factors and workplace exposure to the risk of a bad outcome of occupational asthma?"

A systematic literature search was conducted in March 2010 . We retrieved 177 abstracts. Of these, 67 were assessed as potentially relevant. After full text evaluation, 35 articles that were actually relevant for the question were included in the analysis.

The information obtained was sufficient to establish that older age, high-molecular-weight agents, impaired lung function and longer duration of exposure to the offending agent at the time of diagnosis had a negative role on the outcome of occupational asthma. Atopy and smoking at diagnosis did not seem to influence the outcome of occupational asthma. A limited number of studies considered sex and the pattern of asthmatic reaction on specific inhalation challenge and their findings were contradictory.

KEYWORDS: Atopy, cigarette smoke, duration, lung function, occupational exposure, prognosis

$\mathbf{T}$ he outcome of occupational asthma after diagnosis is often poor. The identification of factors associated with a worse outcome may help in planning appropriate management of the disease, determining its prognosis and in assessing the permanent impairment attributable to occupational exposure. The issue of risk factors associated with the outcome of occupational asthma was considered by recent guidelines but not in a systematic manner. The American College of Chest Physicians (ACCP) [1], the British Occupational Health Research Foundation (BOHRF) [2] and the Agency for Healthcare Research and Quality (AHRQ) [3] agreed that longer symptomatic exposure is related to a worse outcome of occupational asthma. BOHRF concluded that better lung function at diagnosis is related to a better outcome of occupational asthma [2].

The aim of this systematic review was to provide the available evidence from medical literature to answer the key question: "What is the contribution of host factors and workplace exposure to the risk of a bad outcome of occupational asthma?" We considered eight risk factors, in order to determine their respective influence on the prognosis of occupational asthmas: 1) lung function at the time of diagnosis; 2) duration of exposure to the offending agent; 3) atopic status; 4) smoking status at diagnosis; 5) sex; 6) age; 7) type of causing agent; and 8) the pattern of asthmatic reaction on specific inhalation challenge (SIC).

\section{METHODS}

Appropriate search terms were adapted to search Medline via PubMed (table 1).

The final literature search with PubMed was conducted in March 2010. Additional papers were retrieved by cross-referencing. The abstract of each title was independently screened by two occupational medicine specialists for consistency

\section{AFFILIATIONS}

*Dept of Environmental Medicine and Public Health, University of Padova, Padua, Italy.

\# Institute of Environmental and Occupational Medicine, School of Public Health, Århus University, Århus, Denmark.

"For a full list of the members of the Task Force, see the Acknowledgements.

\section{CORRESPONDENCE}

P. Maestrelli

Dipartimento di Medicina Ambientale e Sanità Pubblica

Università degli Studi di Padova via Giustiniani 2 35128 Padova Italy E-mail: piero.maestrelli@unipd.it

Received:

June 072011

Accepted after revision:

July 262011

PROVENANCE

Submitted article, peer reviewed.

European Respiratory Review Print ISSN 0905-9180 Online ISSN 1600-0617 
TABLE 1 Terms used for the PubMed search

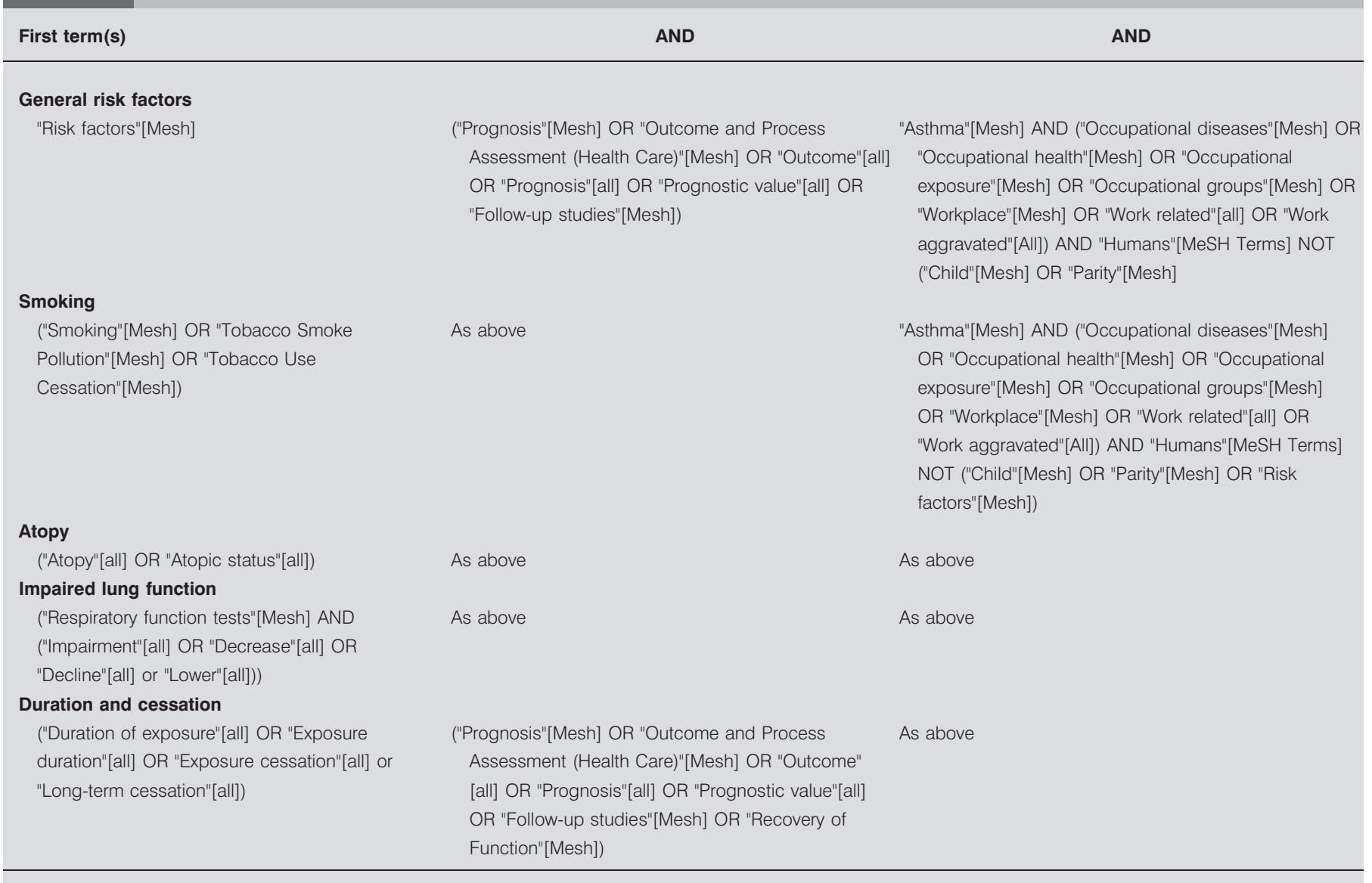

with the aim of the search (P. Mason and V. Schlünssen). The full text of potentially relevant articles was examined according to pre-determined criteria using standardised forms. Two reviewers independently assessed each article. The quality of the studies relevant to the key question was assessed using the Scottish Intercollegiate Guidelines Network (SIGN) grading system (from 1++, highest quality, to 4, lowest quality). Disagreement among reviewers was resolved by discussion and/or consulting a third party, if needed. The heterogeneity of the studies prevented the use of sophisticated analytical methods. Nonetheless, in the synopsis of the data we were able to sufficiently homogenise the information provided and use it for the formulation of statements graded according to the Royal College of General Practitioners (RCGP) three-star system. The evidence and clinical relevance of the recommendations were classified according to the GRADE (Grading of Recommendations Assessment, Development and Evaluation) system adapted by the American Thoracic Society [4]. The methods are extensively described in the paper by BAUR et al. [5]. Search results, as well as the list of considered articles, are included in the evidence tables and are presented in table $\mathrm{O} 3$ in the supplementary material in the paper by BAUR et al. [5].

\section{RESULTS}

148 titles were identified in the systematic literature search. An additional 29 titles that were not included in the search were obtained by cross-referencing the review article by RACHIOTIS et al. [6]. In total, 177 abstracts were considered. Of these, 67 were assessed as potentially relevant for the key question. After full text evaluation, we selected 36 papers that were actually relevant for the key question. The study by AMEILLE et al. [7] was subsequently excluded as the findings were based on results from two papers that were already included $[8,9]$. The evidence table of the 35 papers is included in the study by BAUR et al. [5] (supplementary material, table O3). For each investigated factor, the number of subjects in the positive and negative studies was calculated by adding the number of subjects at follow-up in each study that considered the investigated factor included in the review by RACHIOTIS et al. [6] and in the extended literature search.

\section{Lung function impairment at diagnosis}

Among the 18 articles reviewed, 15 studies detected a significant relationship between low indices of lung function at baseline (nonspecific bronchial hyperresponsiveness (NSBHR): $n=10$; forced expiratory volume in $1 \mathrm{~s}$ (FEV1) or forced vital capacity (FVC): $n=9$; SIC: $n=2$ ) and a worse asthma outcome at follow-up (table 2). One study found that increased bronchial hyperresponsiveness (BHR) at baseline favours a good outcome at follow-up [24]. In contrast, five studies did not find associations between low indices of lung function at baseline (NSBHR: $n=4 ; F E V 1$ or FVC: $n=4$ ) and a worse asthma outcome at follow-up. If the evaluation was restricted to well-conducted studies (grading $2+$ and $2++$ ), the 
TABLE 2 Lung function impairment at diagnosis and outcome of occupational asthma

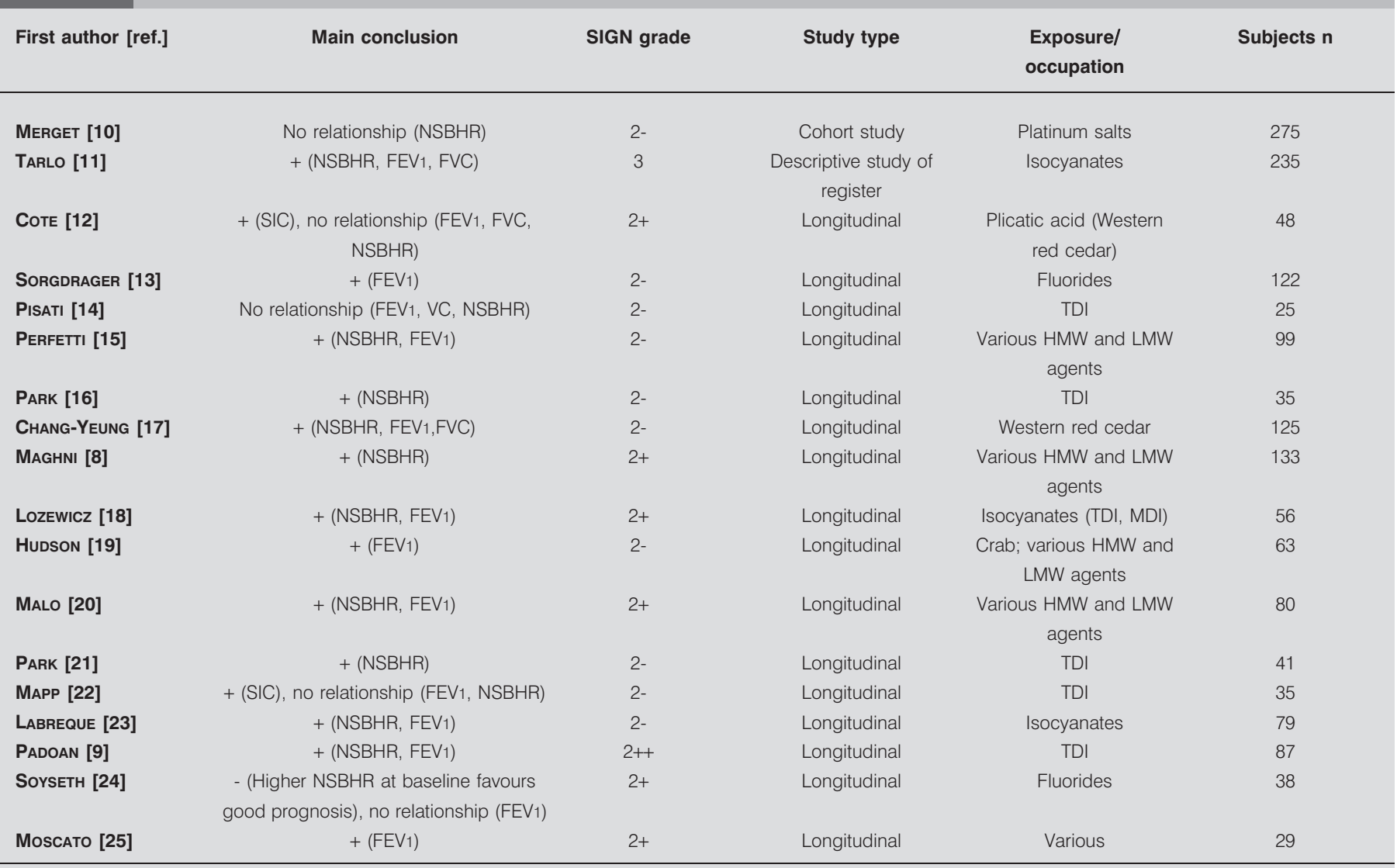

SIGN: Scottish Intercollegiate Guidelines Network; NSBHR: nonspecific bronchial hyperresponsiveness; FEV1: forced expiratory volume in 1 s; FVC: forced vital capacity; SIC: specific inhalation challenge; VC: vital capacity; TDI: toluene diisocyanate; HMW: high molecular weight; LMW: low molecular weight; MDI: methylene diphenyl diisocyanate. +: relationship between worse lung function at baseline (FEV1, FVC, VC, NSBHR and SIC) and worse asthma status at follow-up; - : relationship between worse lung function at baseline (FEV1, FVC, VC, NSBHR and SIC) and better asthma status at follow-up.

number of studies reporting a significant relationship between low indices of lung function at baseline and a worse asthma outcome at follow-up was six versus two studies that reported no relationship (table 2 ).

\section{Duration of occupational exposure}

In addition to the study by RACHIOTIS et al. [6], which includes 14 papers related to the duration of occupational exposure before diagnosis, we evaluated seven papers that detected a significant relationship between duration of exposure and outcome of occupational asthma [11, 13, 14, 21, 26-28]. In contrast, four articles did not find a relationship between duration of exposure and outcome of occupational asthma [24, 29-31]. If the evaluation is restricted to well-conducted studies $(2+, 2++$ or 1-), two studies found a positive association compared to three which did not find any association (table 3). However, the number of subjects in the positive studies (excluding those with grade 3 evidence) largely exceed $(>3,000)$ the number of subjects in the negative studies $(\sim 500)$.

\section{Atopy}

None of the articles reported a relationship between atopy and outcome of occupational asthma (table 4).

\section{Smoking at diagnosis}

11 articles did not find a significant relationship between smoking at diagnosis and outcome of occupational asthma [12, 16, 18, 20, $22-24,28,29,31,39]$. This group includes most of the studies with better $(2+)$ grading. In contrast, four articles reported a relationship between smoking and worse outcome of occupational asthma (table 5) [10, 13, 32, 38].

\section{Sex}

Two papers found no significant relationship between sex and outcome of occupational asthma [21,31]. However, two other studies found a significant relationship between sex and outcome of occupational asthma [20,39]. MALO et al. [20] found female sex to favour good prognosis, while GASSERT et al. [39] found male sex to favour good prognosis (table 6).

\section{Age at diagnosis}

The papers selected by the systematic review were already included in the study by RACHIOTIS et al. [6], which identified an effect of age on asthma outcome (table 7). The number of subjects $(\sim 1,700)$ evaluated in the papers reporting an association between older age at diagnosis and worse outcome of occupational asthma (excluding those with grade 3 
TABLE 3 Duration of occupational exposure and outcome of occupational asthma

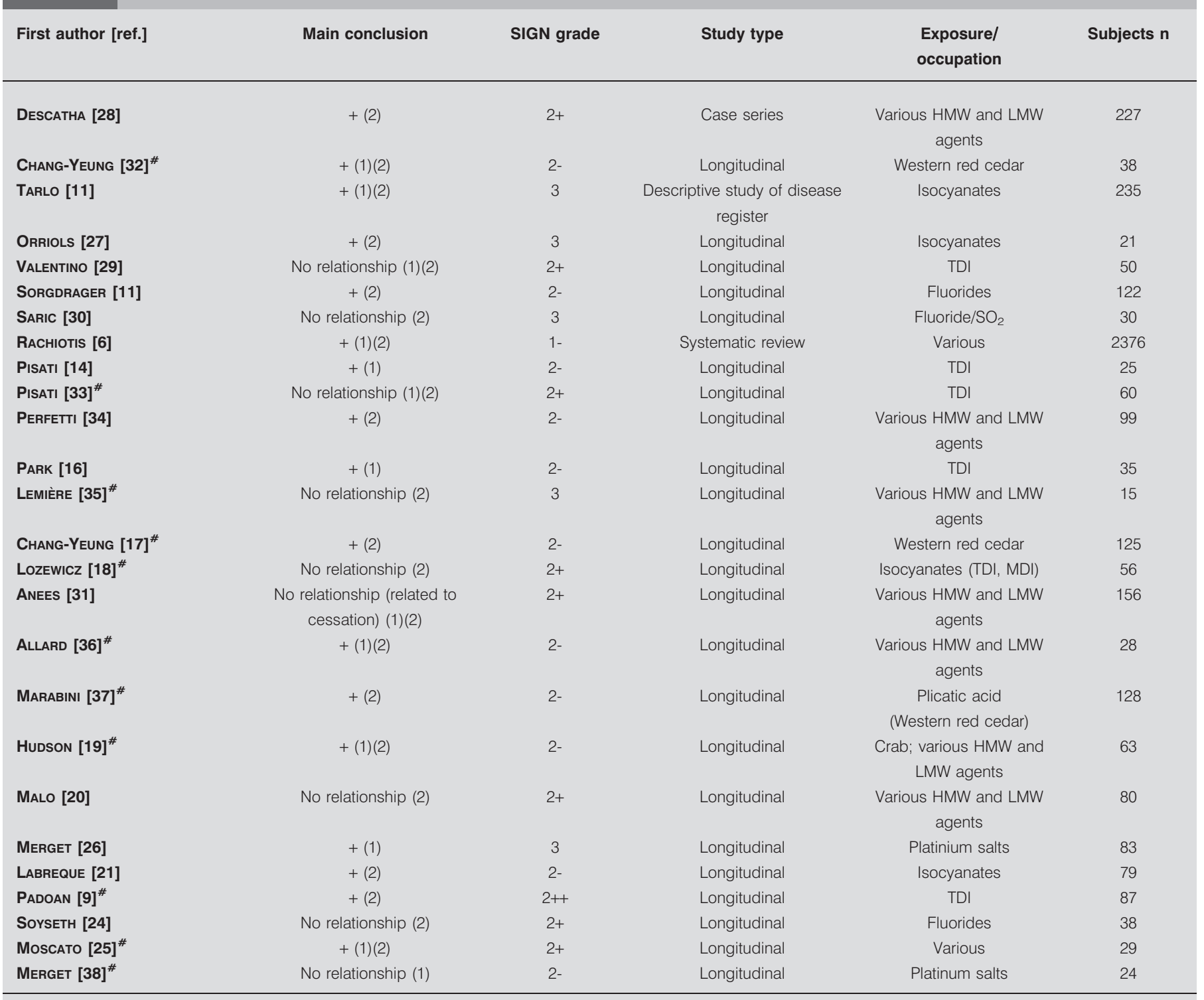

SIGN: Scottish Intercollegiate Guidelines Network; HMW: high molecular weight; LMW: low molecular weight; TDI: toluene diisocyanate; MDI: methylene diphenyl diisocyanate. +: positive relationship between duration of exposure and asthma outcome (shorter exposure results in better outcome); (1): symptomatic exposure before diagnosis; (2): total duration of occupational exposure. ${ }^{\#}$ : these articles are included in the review by RACHIOTIS et al. [6].

evidence) largely exceeds, the number of subjects $(\sim 500)$ included in the studies that did not find such a relationship.

\section{Type of causative agent}

Three studies [19, 34, 39] and the study by RACHIOTIS et al. [6] found a significant relationship between type of agent and outcome of occupational asthma. GASSERT et al. [39] found occupational asthma from the industrial sector to have a worse outcome compared to other sectors. RACHIOTIS et al. [6] and PERFETTI et al. [34] found that patients who are exposed to high-molecular-weight agents are more likely to have persistent BHR. Four studies found no relationship between the type of agent and outcome of occupational asthma $[11,20,28,35]$. The number of studies is limited, but the body of data supporting a positive relationship in the studies graded $2+$ or $1-$ is substantial compared to data revealing no relationship ( $\sim 2,000$ versus $\sim 500$ subjects) (table 8$)$.

\section{Pattern of asthmatic reaction on specific inhalation challenge: late versus early}

Three papers did not find any significant relationship between type of response and outcome of occupational asthma [11, 29, 35]; the grading of these articles is generally low. However, two studies have found late response to worsen the outcome of occupational asthma [22, 40], and COTE et al. [12] detected a relationship with the severity of either early or late asthmatic reactions (table 9). 
TABLE 4 Effect of atopy on outcome of occupational asthma

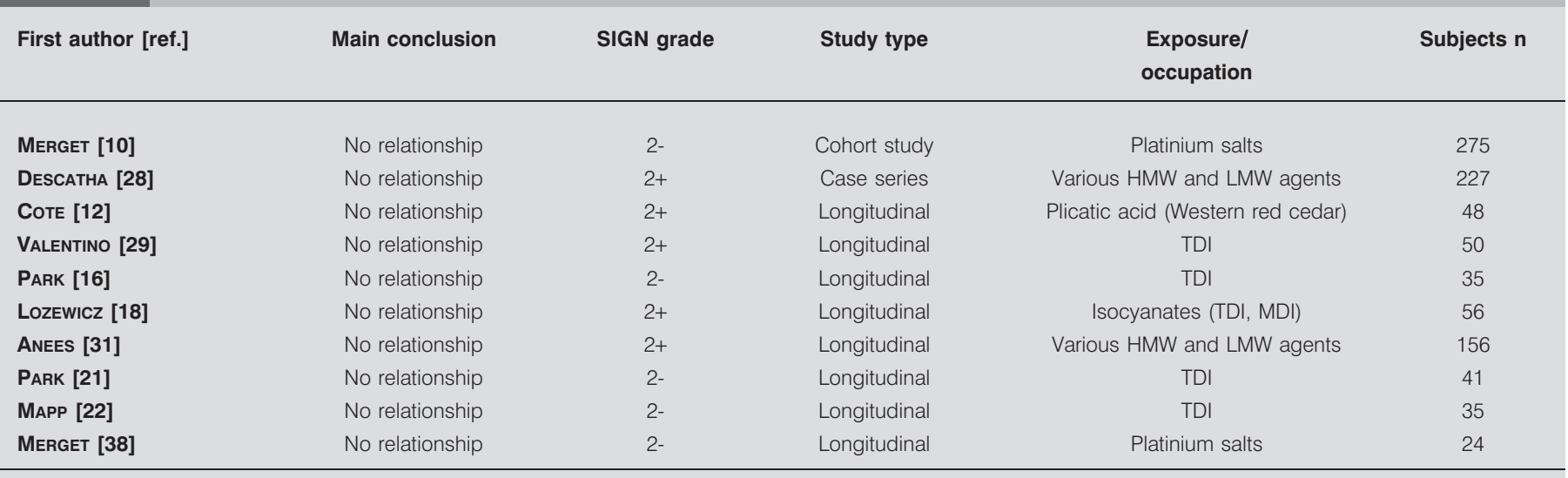

SIGN: Scottish Intercollegiate Guidelines Network; HMW: high molecular weight; LMW: low molecular weight; TDI: toluene diisocyanate; MDI: methylene diphenyl diisocyanate.

\section{DISCUSSION}

The information retrieved from the systematic literature search was sufficient to establish the role of lung function at the time of diagnosis, duration of exposure to the offending agent, atopic status, smoking status at diagnosis, age and type of causative agent on the outcome of occupational asthma. In contrast, a limited number of studies considered sex and the pattern of asthmatic reaction on SIC, and their findings were contradictory.

The following statements summarise the results of our systematic analysis (refer to table $\mathrm{O} 3$ in the Task Force report [5]). The evidence was graded according to the RCGP three-star system.

1) There is a substantial body of data that indicates that lower lung volumes, higher NSBHR or stronger asthmatic response to specific inhalation challenge at diagnosis are risk factors for a bad occupational asthma outcome (moderate evidence: ${ }^{* *}$ ).

The statement is based on 18 articles; seven had SIGN grade $2+$ or $2++$ (table 2) $[8,9,12,18,20,24,25]$. This statement is in agreement with the conclusions of BOHRF [2]. The issue was not considered by ACCP [1] or AHRQ [3].

2) There is a substantial body of data that suggests that a longer symptomatic exposure relates to a worse outcome of occupational asthma (moderate evidence: ${ }^{* *}$ ).

The statement is based on 26 articles, 10 with SIGN grade $2+$ $2++$ or 1 - (table 3$)[6,9,18,20,21,25,28,29,31,33]$. This statement is in agreement with the conclusions of ACCP [1], BOHRF [2] and AHRQ [3].

TABLE 5 Effect of smoking at diagnosis on outcome of occupational asthma

\begin{tabular}{|c|c|c|c|c|c|}
\hline First author [ref.] & Main conclusion & SIGN grade & Study type & Exposure/occupation & Subjects $n$ \\
\hline Merget [10] & + & 2- & Cohort study & Platinum salts & 275 \\
\hline Chang-Yeung [32] & + & $2-$ & Longitudinal & Western red cedar & 38 \\
\hline Cote [12] & No relationship & $2+$ & Longitudinal & Plicatic acid (Western red cedar) & 48 \\
\hline VALENTINo [29] & No relationship & $2+$ & Longitudinal & TDI & 50 \\
\hline LoZEWICZ [18] & No relationship & $2+$ & Longitudinal & Isocyanates (TDI, MDI) & 56 \\
\hline AnEes [31] & No relationship & $2+$ & Longitudinal & Various HMW and LMW agents & 156 \\
\hline MALO [20] & No relationship & $2+$ & Longitudinal & Various HMW and LMW agents & 80 \\
\hline MAPP [22] & No relationship & $2-$ & Longitudinal & TDI & 35 \\
\hline GASSERT [39] & No relationship & 2- & Longitudinal & Various & 55 \\
\hline
\end{tabular}

SIGN: Scottish Intercollegiate Guidelines Network; HMW: high molecular weight; LMW: low molecular weight; TDI: toluene diisocyanate; MDI: methylene diphenyl diisocyanate. +: relationship between smoking at diagnosis and worse asthma outcome. 
TABLE 6 Effect of sex on outcome of occupational asthma

\begin{tabular}{|c|c|c|c|c|c|}
\hline MALO [20] & + (Female sex favours good prognosis) & $2+$ & Longitudinal & Various HMW and LMW agents & 80 \\
\hline PARK [21] & No relationship & $2-$ & Longitudinal & TDI & 41 \\
\hline GASSERT [39] & + (Male sex favours good prognosis) & $2-$ & Longitudinal & Various & 55 \\
\hline
\end{tabular}

SIGN: Scottish Intercollegiate Guidelines Network; HMW: high molecular weight; LMW: low molecular weight; TDI: toluene diisocyanate. +: effect of sex on asthma outcome.

3) There is no relationship between atopy and the outcome of occupational asthma (strong evidence: ${ }^{* * *}$ ).

The statement is based on 10 articles, five with SIGN grade 2+ (table 4) [12, 18, 28, 29, 31]. Atopy was not included in the conclusions of ACCP [1], BOHRF [2] and AHRQ [3].

4) Smoking at the time of diagnosis is not related to the outcome of occupational asthma. Although it is well established that smoking cessation is beneficial for the prognosis of asthma per se, smoking at the time for diagnosis of occupational asthma does not seems to have a major impact on the prognosis (moderate evidence: ${ }^{* *}$ ).

The statement is based on 15 articles, seven with SIGN grade $2+$ (table 5) $[12,18,20,24,28,29,31]$. Smoking was not included in the conclusions of ACCP [1], BOHRF [2] and AHRQ [3].

5) There is a limited body of data that considered sex in the outcome of occupational asthma and the evidence is contradictory (contradictory evidence: ${ }^{*}$ ).

The statement is based on four articles, two with SIGN grade $2+$ (table 6) $[20,31]$. Sex was not included in the conclusions of ACCP [1], BOHR [2] and AHRQ [3].

6) There is a sufficient body of data that indicates that an older age of the patients is associated with poorer prognosis of occupational asthma (moderate evidence: ${ }^{* *}$ ).

The statement is based on six articles, three with SIGN grade $2+$ or 1 - (table 7) $[6,25,28]$. Age was not included in the conclusions of ACCP [1], BOHRF [2] and AHRQ [3].
7) There is a substantial body of data that indicates an effect of the type of causing agents on occupational asthma outcome. High-molecular-weight agents seem to cause longer duration of NSBHR compared to low-molecular-weight allergens (moderate evidence: ${ }^{* *}$ ).

The statement is based on eight articles, three with SIGN grade $2+$ or 1 - (table 8$)[6,20,28]$. This statement is in agreement with the conclusions of ACCP [1]. The issue was not included in the conclusions of BOHRF [2] or AHRQ [3].

8) From the low number of papers it is not clear whether the pattern of asthmatic response affects the prognosis for occupational asthma (limited evidence: *).

The statement is based on six articles, three with SIGN grade $2+$ (table 9) $[12,29,40]$. The issue was not included in the conclusions of ACCP [1], BOHRF [2] and AHRQ [3].

The statements on lung function at diagnosis and duration of exposure to the offending agent before diagnosis are based on a significant number of studies. However, the strength of evidence remains moderate since there is some inconsistency in the results. The conclusion of BOHRF [2] that "the likelihood of improvement or resolution of symptoms or of preventing deterioration is greater in workers who have a relatively normal lung function at the time of diagnosis" is in agreement with our statement. The issue was not considered by ACCP [1] or AHRQ [3].

All recent guidelines have concluded that the probability of a better outcome of occupational asthma is greater in those who have a shorter duration of symptomatic period before diagnosis, and avoid exposure to the offending agent after the diagnosis.

TABLE 7 Effect of age at diagnosis on outcome of occupational asthma

\begin{tabular}{lcccc} 
First author [ref.] & Main conclusion & SIGN grade & Study type & Exposure/occupation \\
\hline DESCATHA [28] & No relationship & $2+$ & Case series & Various HMW and LMW agents \\
RACHIOTIS [6] & + & $1-$ & Systematic review & Various \\
CHANG-YeUNG [17] & + & $2-$ & Longitudinal & Western red cedar \\
PARK [21] $^{\#}$ & No relationship & $2-$ & Longitudinal & TDI \\
MAPP [22] $^{\#}$ & No relationship & $2-$ & Longitudinal & TDI \\
MosCATO [25] $^{\#}$ & + & $2+$ & Longitudinal & 41 \\
\hline
\end{tabular}

SIGN: Scottish Intercollegiate Guidelines Network; HMW: high molecular weight; LMW: low molecular weight; TDI: toluene diisocyanate. +: effect of age on asthma outcome. ${ }^{\#}$ : these articles are included in the review by RACHIOTIS et al. [6]. 
TABLE 8 Effect of type of causing agent on outcome of occupational asthma

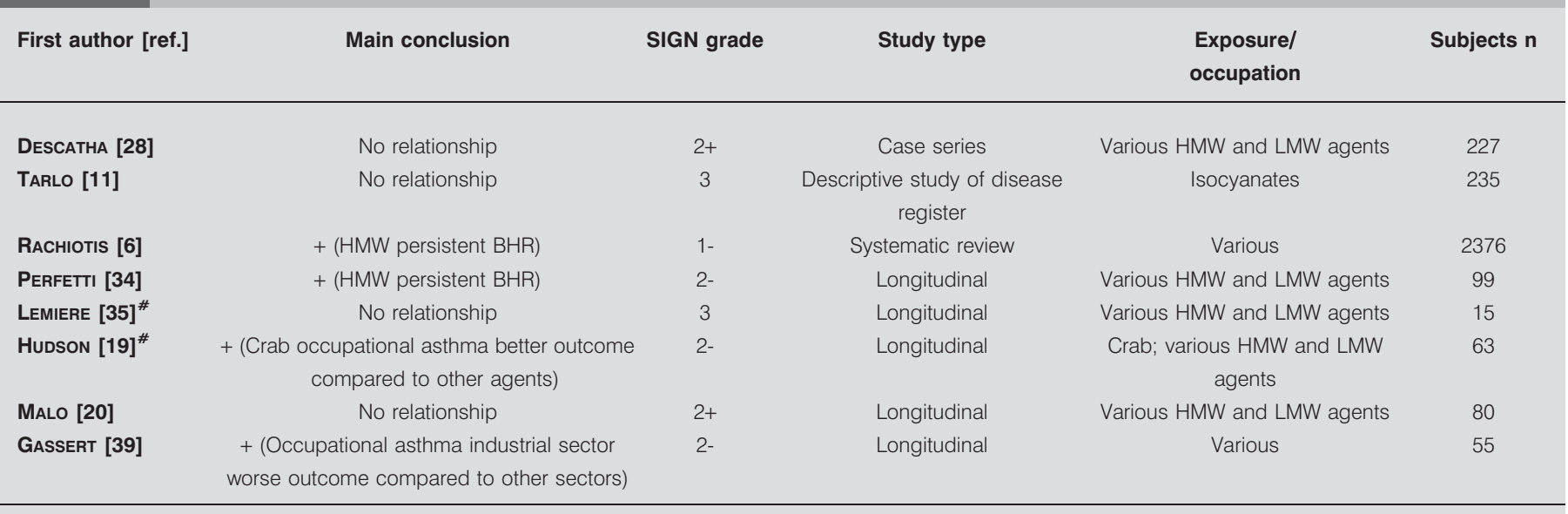

SIGN: Scottish Intercollegiate Guidelines Network; HMW: high molecular weight; LMW: low molecular weight; BHR: bronchial hyperresponsiveness. +: effect of the type of causing agent on asthma outcome. ${ }^{*}$ : these articles are included in the review by RACHOTIS et al. [6].

Although it is well established that atopy is a risk factor for occupational asthma due to high-molecular-weight agents, whereas it is not so for low-molecular-weight causes of occupational asthma, the analysis of data indicated that once occupational asthma has developed, being atopic does not modify the prognosis of the disease irrespective of the nature of the occupational agent. The evidence that the outcome of occupational asthma is not related to the presence of atopy is strong, since the literature is concordant on this conclusion. However, it should be considered that among the studies evaluated, there was an imbalance in favour of occupational asthma due to lowmolecular-weight agents. Atopy was not included in the conclusions of ACCP [1], BOHRF [2] and AHRQ [3].

There was evidence, albeit moderate, that being a smoker at the time of diagnosis of occupational asthma did not influence the prognosis of the disease. This may be surprising considering that asthmatic smokers have an accelerated decline in lung function and poorer response to corticosteroid treatment compared to nonsmokers. Probably the effect of other variables, in particular on persistence or cessation of exposure to the causing agent, on the course of the disease is sufficiently strong to obscure that of cigarette smoke in the small cohorts examined in the studies on occupational asthma. Since pathophysiology and treatment of occupational asthma are comparable to those of non-occupational asthma, it is reasonable to offer the option of smoking cessation to smoking workers when the diagnosis of occupational asthma is made.

There is evidence that older age is related to poorer prognosis of occupational asthma. It remains to be seen whether age is a risk factor per se or that the effect is seen because older workers had been exposed to the workplace environment for longer. Neither smoking habit nor age were considered in previous guidelines by the ACCP [1], BOHRF [2] and AHRQ [3]. The ACCP [1] adopted the findings of RACHIOTIS et al. [6] and stated that the prevalence of persisting NSBHR was significantly higher among those with occupational asthma caused by highmolecular-weight agents compared with those with occupational asthma from low-molecular-weight agents. These conclusions have been confirmed by our extended analysis. The relationship between type of causal agent (high molecular weight versus low molecular weight) and outcome of occupational asthma should be taken cautiously, since RACHIOTIS et al. [6] found that patients exposed to high-molecular-weight agents are more likely to have persistent NSBHR, but the recovery rate after cessation of

TABLE 9 Pattern of asthmatic reaction on specific inhalation challenge (late versus early) and outcome of occupational asthma

$\begin{array}{llcl}\text { First author [ref.] } \quad \text { Main conclusion } & \text { SIGN grade } & \text { Study type } & \begin{array}{c}\text { Exposure/ } \\ \text { occupation }\end{array}\end{array}$

$\begin{array}{lc}\text { TARLo [11] } & \text { No relationship } \\ \text { Cote [12] } & + \text { (Severity of early and late }) \\ \text { VALENTINo [29] } & \text { No relationship } \\ \text { LemIÈRE [35] } & \text { No relationship } \\ \text { MARABINI [40] } & +(\text { Late }) \\ \text { MAPP [23] } & +(\text { Late })\end{array}$

$\begin{array}{ll}3 & \text { Descriptive study of disease register } \\ 2+ & \text { Longitudinal } \\ 2+ & \text { Longitudinal } \\ 3 & \text { Longitudinal } \\ 2+ & \text { Longitudinal } \\ 2- & \text { Longitudinal }\end{array}$

$\begin{array}{cc}\text { Isocyanates } & 235 \\ \text { Plicatic acid (Western red cedar) } & 48 \\ \text { TDI } & 50 \\ \text { Various HMW and LMW agents } & 15 \\ \text { TDI } & 40 \\ \text { TDI } & 35\end{array}$

SIGN: Scottish Intercollegiate Guidelines Network; TDI: toluene diisocyanate; HMW: high molecular weight; LMW: low molecular weight. +: effect of the pattern of asthmatic reaction on asthma outcome. 


\section{TABLE 10 Recommendations}

Recommendation
Health practitioners should consider that an early recognition and diagnosis of occupational asthma

is recommended, since shorter symptomatic periods after diagnosis are associated with a better

outcome

Smoking habit and atopy should not be taken into account in assessing prognosis for medical legal

purposes

More research is needed in order to assess the effects of sex and type of asthmatic response to specific bronchial challenge test on the outcome of occupational asthma
Strength of recommendation

Level of evidence exposure did not differ in the two groups. The type of causing agent was not considered by BOHRF [2] and AHRQ [3].

\section{Future aspects}

More research is needed in order to assess the prognostic value of sex and type of asthmatic response to specific bronchial challenge test at diagnosis. Furthermore, knowledge on the level of exposure is needed in order to assess the effect of duration of exposure in a more qualified way. Finally, most research on risk factors for a bad outcome is performed on a limited number of exposures, i.e. isocyanates and Western red cedar. It is crucial to include other exposures in the research field as well.

In conclusion, based on this systematic review some recommendations can be made regarding risk factors for a bad outcome of occupational asthma (table 10).

\section{SUPPORT STATEMENT}

The work of the Task Force on the Management of Work-related Asthma was funded by the European Respiratory Society.

\section{STATEMENT OF INTEREST}

$\mathrm{V}$. Schlünssen received a fee for speaking at a scientific meeting by GlaxoSmithKline Pharma A/S in 2011.

\section{ACKNOWLEDGEMENTS}

The members of the Task Force are as follows: X. Baur (Chair; Institute for Occupational and Maritime Medicine, University Medical Center Hamburg-Eppendorf, Hamburg, Germany), T. Sigsgaard (Co-Chair; Århus University, Institute of Environmental and Occupational Medicine, School of Public Health, Århus, Denmark), T.B. Aasen (Haukeland University Hospital, Bergen, Norway), P.S. Burge (Dept of Respiratory Medicine, Heart of England NHS Foundation Trust, Birmingham, UK), H. Dressel (Städt. Klinikum München $\mathrm{GmbH}$, Klinikum Neuperlach Zentrum für Akutgeriatrie und Frührehabilitation, Munich, Germany), D. Heederik (Environmental Epidemiology Division, Institute for Risk Assessment Sciences (IRAS), University of Utrecht, Utrecht, the Netherlands), P.K. Henneberger (National Institute for Occupational Safety and Health, Centers for Disease Control and Prevention, Morgantown, WV, USA), P. Maestrelli (Dept of Environmental Medicine and Public Health, University of Padova, Padua, Italy), C.A. Redlich (Yale Occupational/Environmental, New Haven, CT, USA), J. Rooyackers (Netherlands Expertise Center for Occupational Respiratory Disorders - NECORD IRAS NKAL, Utrecht, the Netherlands), V. Schlünssen (Århus University, Århus, Denmark), O. Vandenplas (Dept of Chest Medicine, Mont-Godinne Hospital, Université Catholique de Louvain, Yvoir, Belgium), and D. Wilken (Institute for Occupational and Maritime Medicine, University Medical Center Hamburg-Eppendorf, Hamburg, Germany).

\section{REFERENCES}

1 Tarlo SM, Balmes J, Balkissoon R, et al. Diagnosis and management of work-related asthma: American College of Chest Physicians Consensus Statement. Chest 2008; 134: Suppl. 3, 1s-41s.

2 Nicholson PJ, Cullinan P, Taylor AJ, et al. Evidence based guidelines for the prevention, identification, and management of occupational asthma. Occup Environ Med 2005; 62: 290-299.

3 Beach J, Rowe BH, Blitz S, et al. Diagnosis and Management of Work-related Asthma. Evidence Report/Technology Assessment No. 129. U.S. Department of Health and Human Services, Agency for Healthcare Research and Quality. Edmonton, University of Alberta, 2005.

4 Schünemann HJ, Jaeschke R, Cook DJ, et al. An official ATS statement: grading the quality of evidence and strength of recommendations in ATS guidelines and recommendations. Am J Respir Crit Care Med 2006; 174: 605-614.

5 Baur X, Sigsgaard T, Aasen TB, et al. Guidelines on the management of work-related asthma. Eur Respir J 2012; 39: 529-545.

6 Rachiotis G, Savani R, Brant A, et al. Outcome of occupational asthma after cessation of exposure: a systematic review. Thorax 2007; 62: 147-152.

7 Ameille J, Descatha A. Outcome of occupational asthma. Curr Opin Allergy Clin Immunol 2005; 5: 125-128.

8 Maghni K, Lemiere C, Ghezzo H, et al. Airway inflammation after cessation of exposure to agents causing occupational asthma. Am J Respir Crit Care Med 2004; 169: 367-372.

9 Padoan M, Pozzato V, Simoni M, et al. Long-term follow-up of toluene diisocyanate-induced asthma. Eur Respir J 2003; 21: 637-640.

10 Merget R, Kulzer R, Dierkes-Globisch A, et al. Exposure-effect relationship of platinum salt allergy in a catalyst production plant: conclusions from a 5-year prospective cohort study. J Allergy Clin Immunol 2000; 105: 364-370.

11 Tarlo SM, Banks D, Liss G, et al. Outcome determinants for isocyanate induced occupational asthma among compensation claimants. Occup Environ Med 1997; 54: 756-761.

12 Cote J, Kennedy S, Chan-Yeung M. Outcome of patients with cedar asthma with continuous exposure. Am Rev Respir Dis 1990; 141: 373-376.

13 Sorgdrager B, de Looff AJ, Pal TM, et al. Factors affecting FEV1 in workers with potroom asthma after their removal from exposure. Int Arch Occup Environ Health 2001; 74: 55-58.

14 Pisati G, Baruffini A, Bernabeo F, et al. Rechallenging subjects with occupational asthma due to toluene diisocyanate (TDI), after longterm removal from exposure. Int Arch Occup Environ Health 2007; 80: 298-305.

15 Perfetti L, Hebert J, Lapalme Y, et al. Changes in IgE-mediated allergy to ubiquitous inhalants after removal from or diminution of exposure to the agent causing occupational asthma. Clin Exp Allergy 1998; 28: 66-73. 
16 Park HS, Nahm DH. Prognostic factors for toluene diisocyanateinduced occupational asthma after removal from exposure. Clin Exp Allergy 1997; 27: 1145-1150.

17 Chan-Yeung M, Lam S, Koener S. Clinical features and natural history of occupational asthma due to western red cedar (Thuja plicata). Am J Med 1982; 72: 411-415.

18 Lozewicz S, Assoufi BK, Hawkins R, et al. Outcome of asthma induced by isocyanates. Br J Dis Chest 1987; 81: 14-22.

19 Hudson P, Cartier A, Pineau L, et al. Follow-up of occupational asthma caused by crab and various agents. J Allergy Clin Immunol 1985; 76: 682-688.

20 Malo JL, Ghezzo H. Recovery of methacholine responsiveness after end of exposure in occupational asthma. Am J Respir Crit Care Med 2004; 169: 1304-1307.

21 Park HS, Lee SK, Kim HY, et al. Specific immunoglobulin E and immunoglobulin $G$ antibodies to toluene diisocyanate-human serum albumin conjugate: useful markers for predicting longterm prognosis in toluene diisocyanate-induced asthma. Clin Exp Allergy 2002; 32: 551-555.

22 Mapp CE, Corona PC, De Marzo N, et al. Persistent asthma due to isocyanates. A follow-up study of subjects with occupational asthma due to toluene diisocyanate (TDI). Am Rev Respir Dis 1988; 137: 1326-1329.

23 Labrecque $\mathrm{M}$, Khemici E, Cartier A, et al. Impairment in workers with isocyanate-induced occupational asthma and removed from exposure in the province of Quebec between 1985 and 2002. J Occup Environ Med 2006; 48: 1093-1098.

24 Soyseth V, Kongerud J, Aalen OO, et al. Bronchial responsiveness decreases in relocated aluminum potroom workers compared with workers who continue their potroom exposure. Int Arch Occup Environ Health 1995; 67: 53-57.

25 Moscato G, Bertoletti R, Biscaldi G, et al. Occupational asthma: fate and management after the diagnosis. G Ital Med Lav 1993; 15: 27-31.

26 Merget R, Schulte A, Gebler A, et al. Outcome of occupational asthma due to platinum salts after transferral to low-exposure areas. Int Arch Occup Environ Health 1999; 72: 33-39.

27 Orriols R, Drobnic ME, Munoz X, et al. Asma ocupacional por isocianatos: estudio de 21 pacientes [Occupational asthma due to isocyanates: a study of 21 patients]. Med Clin (Barc) 1999; 113: 659-662.

28 Descatha A, Leproust H, Choudat D, et al. Factors associated with severity of occupational asthma with a latency period at diagnosis. Allergy 2007; 62: 795-801.
29 Valentino M, Rapisarda V. Evoluzione dell'asma da isocianati in rapporto alla cessazione dell'esposizione: studio longitudinale su 50 soggetti [Course of isocyanate-induced asthma in relation to exposure cessation: longitudinal study of 50 subjects]. G Ital Med Lav Ergon 2002; 24: 26-31.

30 Saric M, Marelja J. Bronchial hyperreactivity in potroom workers and prognosis after stopping exposure. Br J Ind Med 1991; 48: 653-655.

31 Anees W, Moore VC, Burge PS. FEV1 decline in occupational asthma. Thorax 2006; 61: 751-755.

32 Chan-Yeung M. Fate of occupational asthma. A follow-up study of patients with occupational asthma due to Western Red Cedar (Thuja plicata). Am Rev Respir Dis 1977; 116: 1023-1029.

33 Pisati G, Baruffini A, Zedda S. Toluene diisocyanate induced asthma: outcome according to persistence or cessation of exposure. Br J Ind Med 1993; 50: 60-64.

34 Perfetti L, Cartier A, Ghezzo H, et al. Follow-up of occupational asthma after removal from or diminution of exposure to the responsible agent: relevance of the length of the interval from cessation of exposure. Chest 1998; 114: 398-403.

35 Lemière C, Cartier A, Dolovich J, et al. Outcome of specific bronchial responsiveness to occupational agents after removal from exposure. Am J Respir Crit Care Med 1996; 154: 329-333.

36 Allard C, Cartier A, Ghezzo H, et al. Occupational asthma due to various agents. Absence of clinical and functional improvement at an interval of four or more years after cessation of exposure. Chest 1989; 96: 1046-1049.

37 Marabini A, Dimich-Ward H, Kwan SY, et al. Clinical and socioeconomic features of subjects with red cedar asthma. A follow-up study. Chest 1993; 104: 821-824.

38 Merget R, Reineke M, Rueckmann A, et al. Nonspecific and specific bronchial responsiveness in occupational asthma caused by platinum salts after allergen avoidance. Am J Respir Crit Care Med 1994; 150: 1146-1149.

39 Gassert $\mathrm{TH}, \mathrm{Hu} \mathrm{H}$, Kelsey KT, et al. Long-term health and employment outcomes of occupational asthma and their determinants. J Occup Environ Med 1998; 40: 481-491.

40 Marabini A, Brugnami G, Curradi F, et al. Risposta al test di provocazione bronchiale specifica ed evoluzione dell'asma professionale. Studio longitudinale in soggetti con asma da toluendiisocianato (TDI) [The response to a specific bronchial provocation test and the evolution of occupational asthma. A longitudinal study in subjects with toluene diisocyanate-induced asthma]. Med Lav 1994; 85: 134-141. 